\title{
Inhibition of telomerase activity and cell growth by free and nanoliposomal forms of punicalagin in human leukemia cell line K562
}

\author{
Amir Gharib ${ }^{1^{*}}$, Zohreh Faezizadeh ${ }^{1}$ and Masoud Godarzee ${ }^{2}$ \\ ${ }^{1}$ Department of Laboratory Sciences, Borujerd Branch, Islamic Azad University, Borujerd, Iran, ${ }^{2}$ Department of Biology, \\ Borujerd Branch, Islamic Azad University, Borujerd, Iran
}

*For correspondence: Email: amirgharib@gmail.com; Tel: +986623500201; Fax: +986624453013

\begin{abstract}
Purpose: To prepare punicalagin-loaded nanoliposome and compare its anti-telomerase activity in K562 cell line with that of free punicalagin.

Methods: Punicalagin-loaded nanoliposomes were prepared by extrusion method, and the efficiency of punicalagin entrapment was determined by high-performance liquid chromatography (HPLC) method. The anti-proliferation effect of the punicalagin in the free and nanoliposomal forms at various doses $(0$ $100 \mu \mathrm{g} / \mathrm{mL})$ and times $(0-72 \mathrm{~h})$ on $\mathrm{K5} 62$ cell line was investigated using 3-(4,5-dimethylthiazol-2-yl)2,5-diphenyl tetrazolium bromide ((MTT) assay. Changes in telomerase activity, following treatment with punicalagin, of the free and nanoliposomal forms were measured by telomeric repeat amplification protocol-enzyme-linked immunosorbent assay.

Results: The entrapment efficiency of punicalagin was $86.7 \pm 1 \%$. Treatment of K562 cells with punicalagin, particularly in the nanoliposomal form, resulted in significant induction of apoptosis and inhibition of cell growth. Furthermore, the telomerase activity of the nanoliposomal punicalagin-treated cells was significantly inhibited in a time- and dose-dependent manner.

Conclusion: Punicalagin shows a novel mechanism of anti-telomerase activity, particularly in the nanoliposomal form, and may provide a basis for the future development of anti-cancer therapy.
\end{abstract}

Keywords: Punicalagin, Apoptosis, Anti-proliferative, Nanoliposome, Telomerase, Leukemia

Tropical Journal of Pharmaceutical Research is indexed by Science Citation Index (SciSearch), Scopus, International Pharmaceutical Abstract, Chemical Abstracts, Embase, Index Copernicus, EBSCO, African Index Medicus, JournalSeek, Journal Citation Reports/Science Edition, Directory of Open Access Journals (DOAJ), African Journal Online, Bioline International, Open-J-Gate and Pharmacy Abstracts

\section{INTRODUCTION}

Telomerase is a reverse transcriptase enzyme responsible for the renewal of chromosomal ends, the so-called telomeres [1]. Increase in telomerase activity is closely related to expression of subunit human telomerase reverse transcriptase (hTERT) which is widely expressed in almost all tumor-derived human cell lines, and present in at least $85 \%$ of human tumor samples [2]. Previous studies have showed that expression of hTERT and activation of telomerase is a crucial step in tumorigenesis [3]. It has been reported that inhibition of telomerase triggers apoptotic cell death in various cancer cell types [4].

In cancer therapy research, many different synthetic chemical agents have been proposed for telomerase inhibition but most of these compounds have severe toxic side effects on normal cells [5]. As a result, extensive studies have been carried out in search of compounds that are capable of inhibiting telomerase activity 
and retarding growth of cancer cells without affecting normal cells [6,7]. Many studies have shown that certain plant-derived compounds have this property and were able to inhibit telomerase activity in several cancer cell lines without affecting normal cells [8,9].

Punicalagin (Figure 1) a phenolic compound is found in some plants such as Punica granatum, Terminalia catappa and Combretum molle [10]. It has inhibitory effect on different kinds of cancer cells including prostate and colon cancer cells $[11,12]$. However, the in vivo instability of punicalagin has restricted its use in biomedical research [13]. Previous studies showed that encapsulation of plant-derived materials in nanocarriers such as nanoliposomes markedly reduced their in vivo instability and increased their effectiveness [14,15].

A liposome is a colloidal and spherical vesicle that can be used as a vehicle for the administration of pharmaceutical drugs and nutrients [16]. Liposomes have diameter ranging from a few nanometers to several micrometers, and compose of natural phospholipids and other lipids, such as cholesterol $[14,15]$. To date, the anti-proliferative and anti-telomerase activities of punicalagin in the free and nanoliposomal forms against human K562 cell line have not yet been studied. The aim of the present study was to prepare punicalagin-loaded nanoliposomes and investigate their in vitro antiproliferative and antitelomerase activities against human leukemia cell line K562.

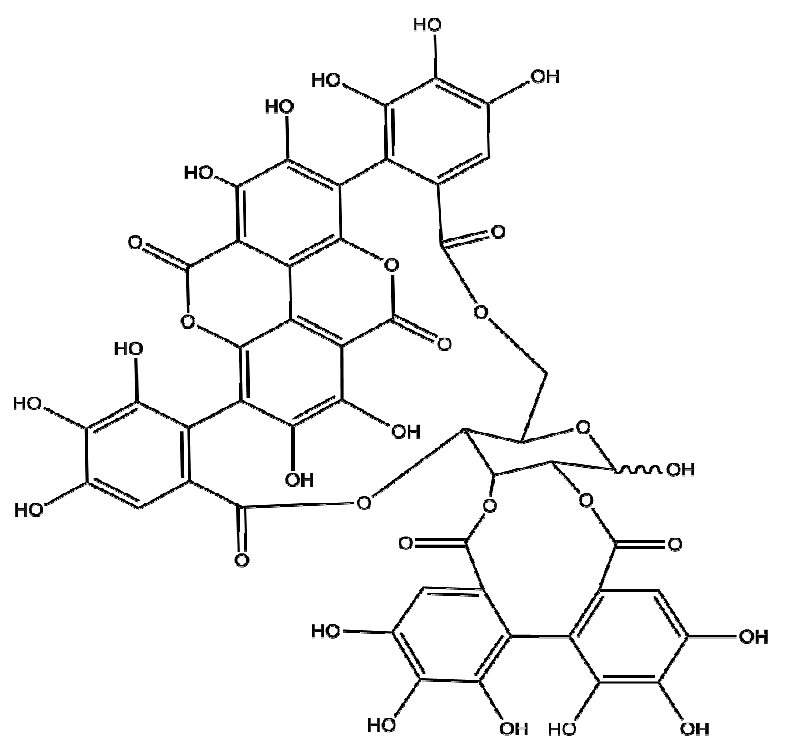

Figure 1: Punicalagin chemical structure

\section{EXPERIMENTAL}

\section{Materials}

Fetal bovine serum (FBS), RPMI-1640, trypan blue, streptomycin and penicillin were purchased from Gibco BRL (Gaithersburg, MD, USA). Punicalagin (purity $\geq 98 \%$ ), soy lecithin, cholesterol and Hoechst 33342 were purchased from Sigma (St. Louis, MO, USA). TeloTAGGG telomerase polymerase chain reaction (PCR)enzyme-linked immunosorbent assay (ELISA) Plus kit and Annexin V-propidium iodide (PI) apoptosis Detection Kit were obtained from Roche (Applied Science, Germany). Acetic acid and mwere purchased from Merck (Darmstadt, Germany).

\section{Preparation of punicalagin-loaded nanoli- posomes}

Punicalagin-loaded nanoliposomes were prepared by extrusion method, as described previously with some modifications [16]. Briefly, soy lecithin and cholesterol (5:1 molar ratio) were dissolved in chloroform and then dried to a lipid film with a rotary evaporator (Brinkman) at $30{ }^{\circ} \mathrm{C}$ under controlled vacuum. The dried lipids were dispersed by agitation in $1 \mathrm{~mL}$ of punicalagin solution $(100 \mu \mathrm{g} / \mathrm{mL})$ and sonicated at $4{ }^{\circ} \mathrm{C}$ in ultrasonic bath (Braun-sonic 2000).

Thereafter, punicalagin-loaded nanoliposomes were obtained by extruding of nanoliposomal suspension 10 times through a polycarbonate membrane filter with $100 \mathrm{~nm}$ pores. Excess free punicalagin and larger lipid aggregation were separated by ultracentrifugation $(100,000 \mathrm{~g}, 30$ $\mathrm{min})$. The control nanoliposomes were prepared similarly, but PBS ( $\mathrm{pH} 7.4)$ was used instead of the punicalagin solution.

\section{Characterization of nanoliposomes}

Punicalagin content of the nanoliposomes was determined by HPLC method [17] following dissolution in $0.1 \%$ Triton $\mathrm{X}-100$. After dissolution, $20 \mu \mathrm{L}$ of lysate was injected into the HPLC column (C18, $4.5 \times 150 \mathrm{~mm}, 5 \mu \mathrm{m}$, Phenomenex, Torrance, USA). The diode array UV detector and the mobile phases, including water (A); $88 \%$ water + $12 \%$ methanol (B); 20 $\%$ water $+80 \%$ methanol (C); methanol (D) was used. The elution started with $100 \%$ A (5 min) and a gradient was used to obtain $100 \% \mathrm{~B}$ at 10 min, holding it isocratic for 3 more minutes and from 13 to $35 \mathrm{~min}$. Subsequently, a linear gradient was used to obtain $50 \% \mathrm{~B}$ and $50 \% \mathrm{C}$, and then $100 \% \mathrm{C}$ at $40 \mathrm{~min}$ and the column was washed with $100 \% \mathrm{D}$ at $42 \mathrm{~min}$. The flow rate 
was $0.9 \mathrm{~mL} / \mathrm{min}$. Finally, the loading $(\mathrm{L})$ of punicalagin was calculated as in Eq 1.

$L(\%)=\{(\mathrm{WnV}) /(\mathrm{VWi})\} 100$

where $\mathrm{Wn}$ is the amount of punicalagin in nanoliposomes, $\mathrm{V}$ the total sample volume tested and $\mathrm{Wi}$ the initial amount of punicalagin used in preparing the nanoliposomal formulation. The polydispersity index, size distribution, zeta potential and mean particle size of the nanoliposomes was evaluated using a Malvern zetasizer (Malvern Instrument, Worcestershire, UK) apparatus, as reported previously [8]. The analysis of the size and shape of the punicalaginloaded nanoliposomes were carried out by cryoTEM, as previously described [18].

\section{Cell culture}

The human chronic myelogenic leukemia cell line K562 was purchased from Pasteur Institute of Iran (Tehran, Iran). The K562 cells were maintained in RPMI-1640 medium supplemented with $10 \%$ FBS along with streptomycin (100 $\mu \mathrm{g} / \mathrm{ml}$ ) and penicillin (100 units $/ \mathrm{ml}$ ) and were grown in a humidified incubator $\left(37^{\circ} \mathrm{C}\right.$ and $5 \%$ $\mathrm{CO}_{2}$ ). Punicalagin was dissolved in the deionized water to obtain a $100 \mu \mathrm{g} / \mathrm{ml}$ stock solution and all subsequent dilutions were made in RPMI medium.

\section{Cell proliferation assay}

Cell proliferation was determined using the 3(4,5-dimethylthiazol-2-yl)-2,5-diphenyl

tetrazolium bromide (MTT) assay as previously described [19]. In brief, $5 \times 10^{3}$ cells were incubated in 96 well plates in the presence of different concentrations of punicalagin in the nanoliposomal and free forms $(0,10,50$ and 100 $\mu \mathrm{g} / \mathrm{mL}$ ) for 24,48 , and $72 \mathrm{~h}$ in a final volume of $200 \mu \mathrm{l}$. At the end of the treatment, $20 \mu \mathrm{L}$ of MTT (5 mg/mL in PBS) was added to each well and then incubated at $37^{\circ} \mathrm{C}$ for an additional $2 \mathrm{~h}$. The resultant precipitate was dissolved in $200 \mu \mathrm{L}$ of DMSO and the viability of cells was assessed by measuring the optical density at $570 \mathrm{~nm}$. Three replicates were done for each concentration of punicalagin in the free and nanoliposomal forms.

\section{Nuclear staining with Hoechst 33342}

K562 cells were incubated with punicalagin in the free and nanoliposomal forms $(0,10,50$ and 100 $\mu \mathrm{g} / \mathrm{mL}$ ) for $72 \mathrm{~h}$ and washed with PBS buffer. After fixation in freshly prepared ice-cold paraformaldehyde $(0.1 \%)$ for $10 \mathrm{~min}$, the cells were stained with Hoechst $33342(50 \mu \mathrm{g} / \mathrm{mL})$ for $1 \mathrm{~min}$ in the dark and morphologic changes were observed under the fluorescent microscope. Thereafter, the percentage of apoptotic cells was assessed after counting at least 100 cells per treatment group.

\section{Flow cytometric analysis}

The K562 cells were treated with varying concentrations of the punicalagin and its nanoliposomal form $(0,10,50$ and $100 \mu \mathrm{g} / \mathrm{mL})$ for $72 \mathrm{~h}$. At the end of each treatment, the cells were collected and quantitative apoptotic death assay was done by Annexin $\mathrm{V}$ and $\mathrm{PI}$ staining following the manufacturer's protocol. Apoptotic cells were measured immediately by flow cytometry.

\section{Telomerase activity assay}

The K562 cells were first treated with different concentrations $(0,10,50$ and $100 \mu \mathrm{g} / \mathrm{mL})$ of the punicalagin in the encapsulated and free forms for $72 \mathrm{~h}$. Moreover, in order to investigate the effect of different incubation times on telomerase activity, punicalagin in the free and encapsulated forms at $100 \mu \mathrm{g} / \mathrm{mL}$ was incubated for different time intervals $(0,24,48$ and $72 \mathrm{~h})$. At the end of each treatment, the cells were harvested and washed twice with washing buffer and lysed in the lysate buffer. The protein concentration was determined using Bradford method [20]. The telomerase activity was assessed using TeloTAGGG telomerase PCR-ELISA plus Detection Kit according to the manufacturer's protocol (Roche Applied Science, Germany). In the presence of biotin-labeled primers cell extracts were incubated for $30 \mathrm{~min}$ and the telomeric repeats were built by cell-extracted telomerase.

Thereafter, the elongated products as well as a special internal standard were amplified by PCR. The PCR products were denatured and split in two aliquots which were separately hybridized to digoxigenin-labeled detection specific probes and allowed to bind to a streptavidin coated, 96-well plate. Then the biotin-labeled PCR products were detected using peroxidase-conjugated antibody. Absorbance of the developed blue color was measured at $450 \mathrm{~nm}$ by STAT-FAX 3200 ELISA reader (Awareness Technology, Inc., USA). As the negative control, each extract was heated for $10 \mathrm{~min}$ at $95{ }^{\circ} \mathrm{C}$ prior to the PCR step. Thereafter, relative telomerase activity (RTA) of each sample was determined according to the instruction of TeloTAGGG Telomerase PCRELISA PLUS kit. 


\section{Statistical analysis}

The results are presented as mean \pm standard deviation (SD). Analysis of variance was done to determine significant level among the test groups and differences with $p<0.05$ were considered statistically significant. Data were analyzed using SPSS software (version 19.0, SPSS, Inc., IL, USA).

\section{RESULTS}

The data revealed that percentage of punicalagin entrapment efficiency was $86.7 \pm 1 \%$. Table 1 shows the mean particle size, zeta-potential, and polydispersity index of empty and punicalaginloaded nanoliposomes. The size homogeneity of empty and loaded nanoliposomes suggested that punicalagin was entrapped into nanoliposomes, according to previous reports [14-16]. In addition, zeta-potential and polydispersity index of the punicalagin-loaded nanoliposomes showed that nanoliposomes have appropriate stability in the aqueous dispersion [14].

The viability of the K562 cells after treatment with punicalagin in the free and encapsulated forms was examined by MTT assay. The results revealed that the cell proliferation was inhibited in the K562 cells in a time- and dose-dependent manner (Figure 2). In all conditions, the punicalagin-loaded nanoliposomes were more effective than those of free punicalagin on $\mathrm{K} 562$ cell growth. As shown in Figure 2, the extent of inhibition increased significantly at $24 \mathrm{~h}$ with the lowest concentration of punicalagin in the encapsulated and free forms which continued to rise at 48 and $72 \mathrm{~h}$ durations at the maximum concentration.

Cryo-TEM analysis revealed that nanoliposomes had a fine homogeneity and were spherical in shape (Figure 3). Under a fluorescence microscope, punicalagin-treated cells stained after $72 \mathrm{~h}$ showed characteristic apoptotic features such as chromatin condensation and nuclear fragmentation (Figure $4 \mathrm{c}$ and $4 \mathrm{~d}$ ). In particular, in the presence of punicalagin-loaded nanoliposomes, the percentage of the apoptotic cells was increased in a dose-dependent manner and percentage of apoptotic cells was also higher than in those exposed to free punicalagin (Figure 4a).

\section{Flow cytometry results}

As shown in the representative FACS analysis scatter-grams, cells treated with punicalagin, particularly in the encapsulated form at 10, 50 and $100 \mu \mathrm{g} / \mathrm{mL}$ for $72 \mathrm{~h}$ showed strong shift from viable cells to the early and late apoptotic cells (Figure 5).

When compared to untreated cells, the RTA of K562 cells were significantly suppressed in a concentration and time-dependent manner after treatment with punicalagin, particularly in the loaded form (Figures 6 and 7). Compared to control group, results showed that RTA of cells treated with $100 \mu \mathrm{g} / \mathrm{mL}$ punicalagin in the free and nanoliposomal forms at $72 \mathrm{~h}$ was reduced to $22.5 \pm 1.5$ and $13.1 \pm 0.5 \%$, respectively (Figure 6). Similarly, as shown in Figure 7, RTA of K562 cells treated with punicalagin in the free and loaded forms was reduced to $28.2 \pm 1.2 \%$ and $17.1 \% \pm 1.8$ at $48 \mathrm{~h}$ respectively, as compared to control group $(p<0.05)$.

\section{DISCUSSION}

Punicalagin is an ellagitannin, found in Pomegranate (Punica granatum L.) and some other plants. [10]. Evidence of the health benefit of punicalagin are manifested in its strong antioxidative, anti-cancer, anti-inflammatory, and anti-atherosclerotic activities [11,12]. Punicalagin is a major antioxidant polyphenol in pomegranate juice, where it may reach levels of up to $1 \mathrm{~g} / \mathrm{L}$ of juice [21]. It has potential antiviral effect against enterovirus 71 and could be used for the therapy of various immune pathologies [22].

Moreover, punicalagin has an inhibitory effect on some cancer cells, including HT-29 and HCT116 colon cancer cells [23]. It was reported that telomerase activity was an important marker for tumorigenesis and inhibition of this enzyme could be used for the development of anti-proliferative agents and anti-tumor drugs [1-4].

Table 1: Particle size, zeta-potential and polydispersity index of the empty and punicalagin-loaded nanoliposomes

\begin{tabular}{lccc}
\hline Formulation & $\begin{array}{c}\text { Mean particle size } \\
(\mathbf{n m})\end{array}$ & $\begin{array}{c}\text { Zeta-potential } \\
(\mathbf{m V})\end{array}$ & $\begin{array}{c}\text { Polydispersity } \\
\text { index }\end{array}$ \\
\hline Empty nanoliposomes & $91.7 \pm 0.15$ & $-1.03 \pm 0.08$ & $0.16 \pm 0.04$ \\
Punicalagin-loaded & $95.7 \pm 0.15$ & $-1.24 \pm 0.13$ & $0.16 \pm 0.05$ \\
nanoliposomes & & & \\
\hline
\end{tabular}




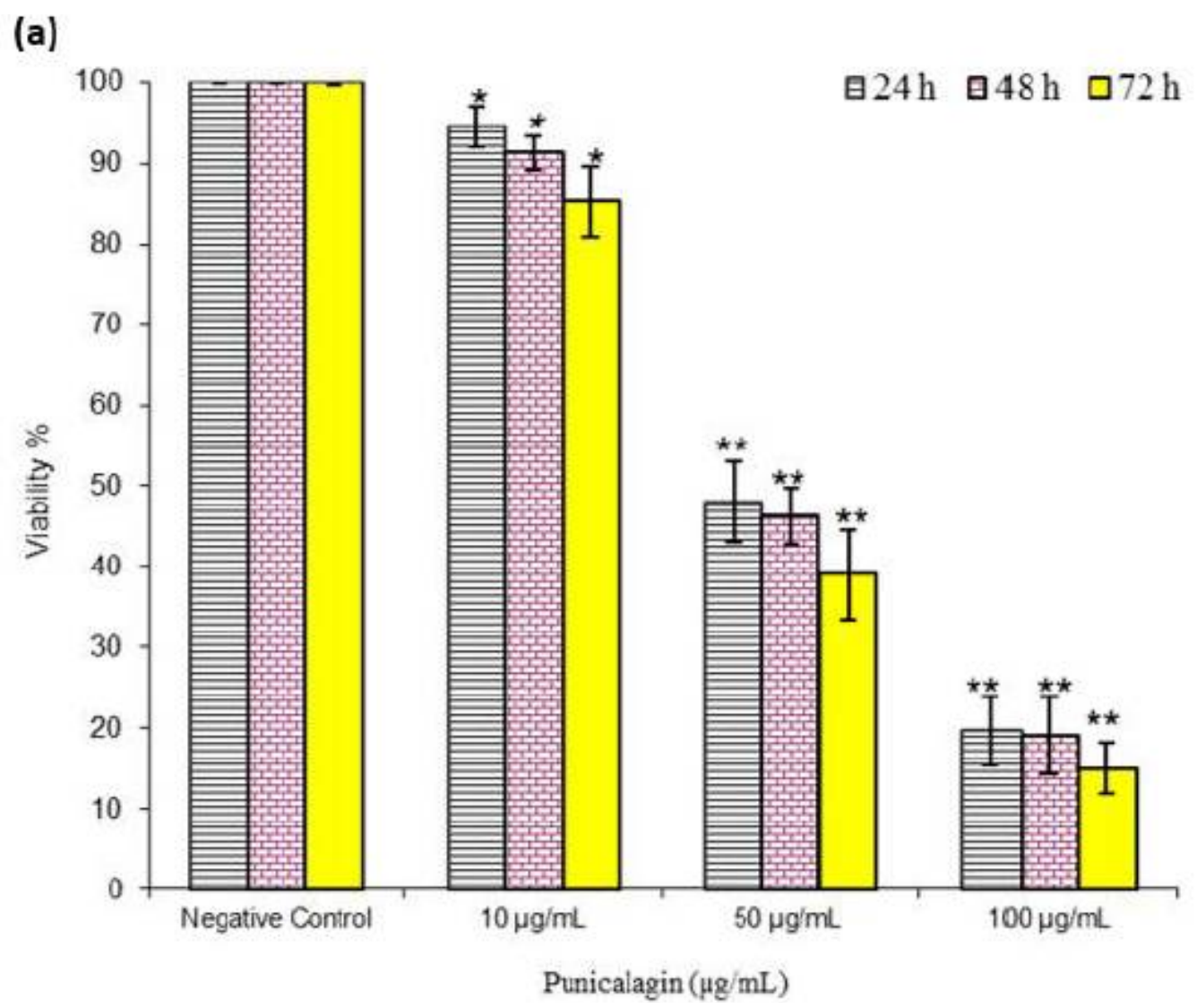

(b)

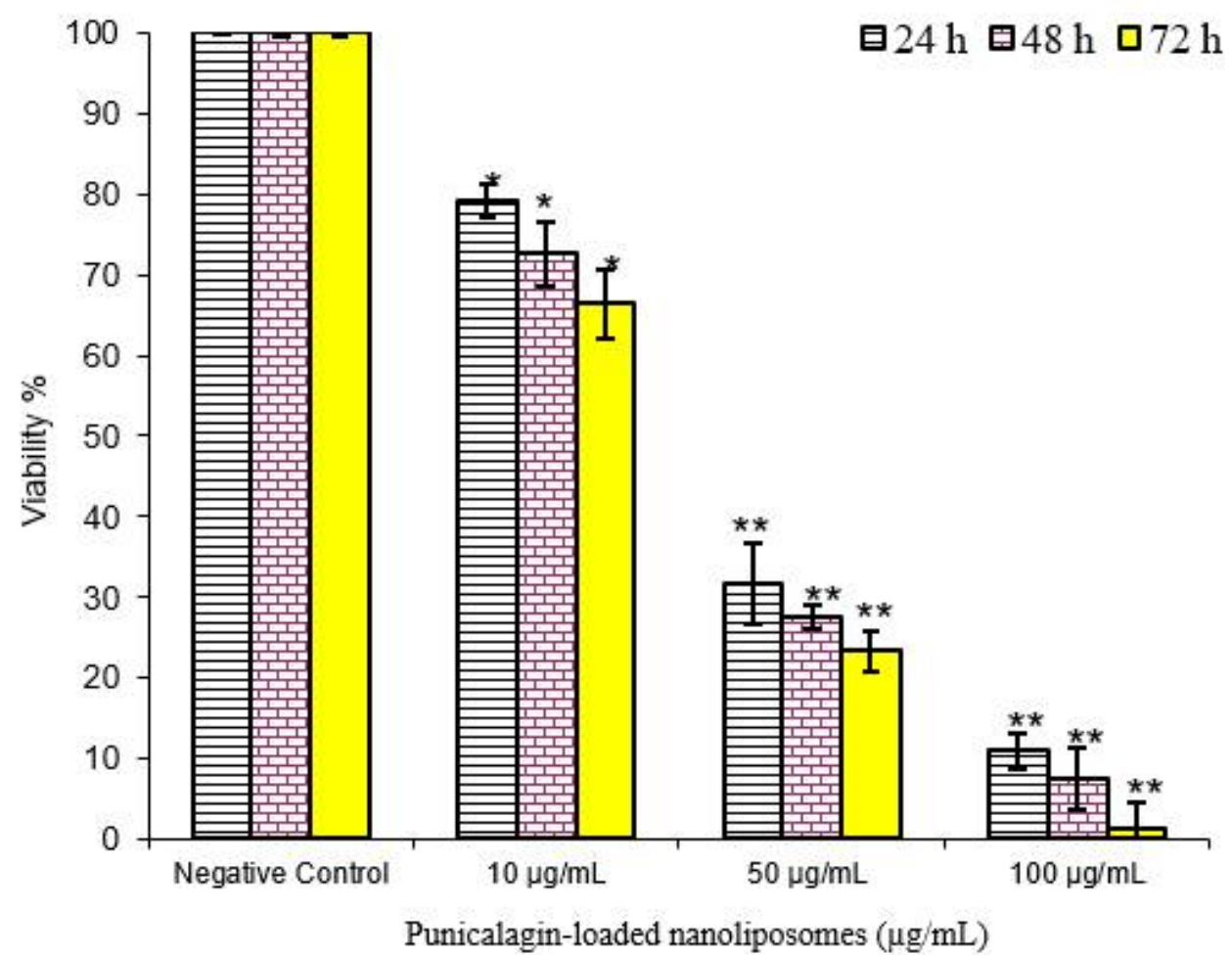

Figure 3: Dose- and time-dependent inhibition of $\mathrm{K} 562$ cell growth by punicalagin in the free (a) and nanoliposomal (b) forms. Data are expressed as mean \pm standard deviation from three independent experiments $\left({ }^{*} p<0.05\right.$ and $\left.{ }^{* *} p<0.001\right)$ 


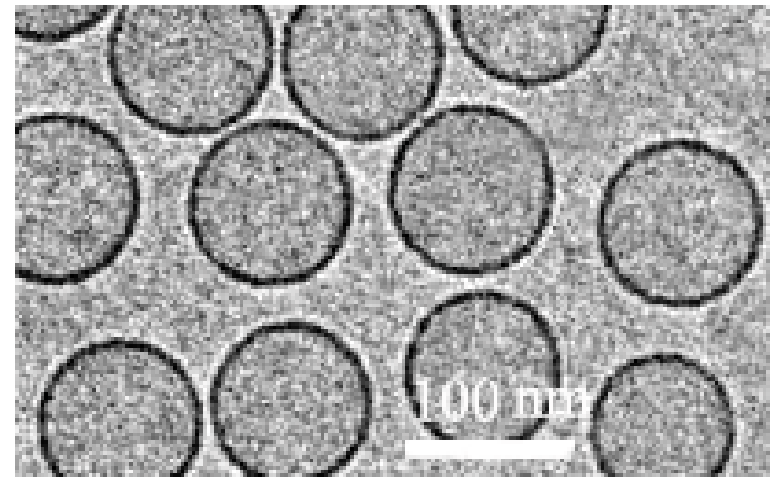

Figure 3: Cryo-transmission electron micrograph of the nanoliposomal punicalagin
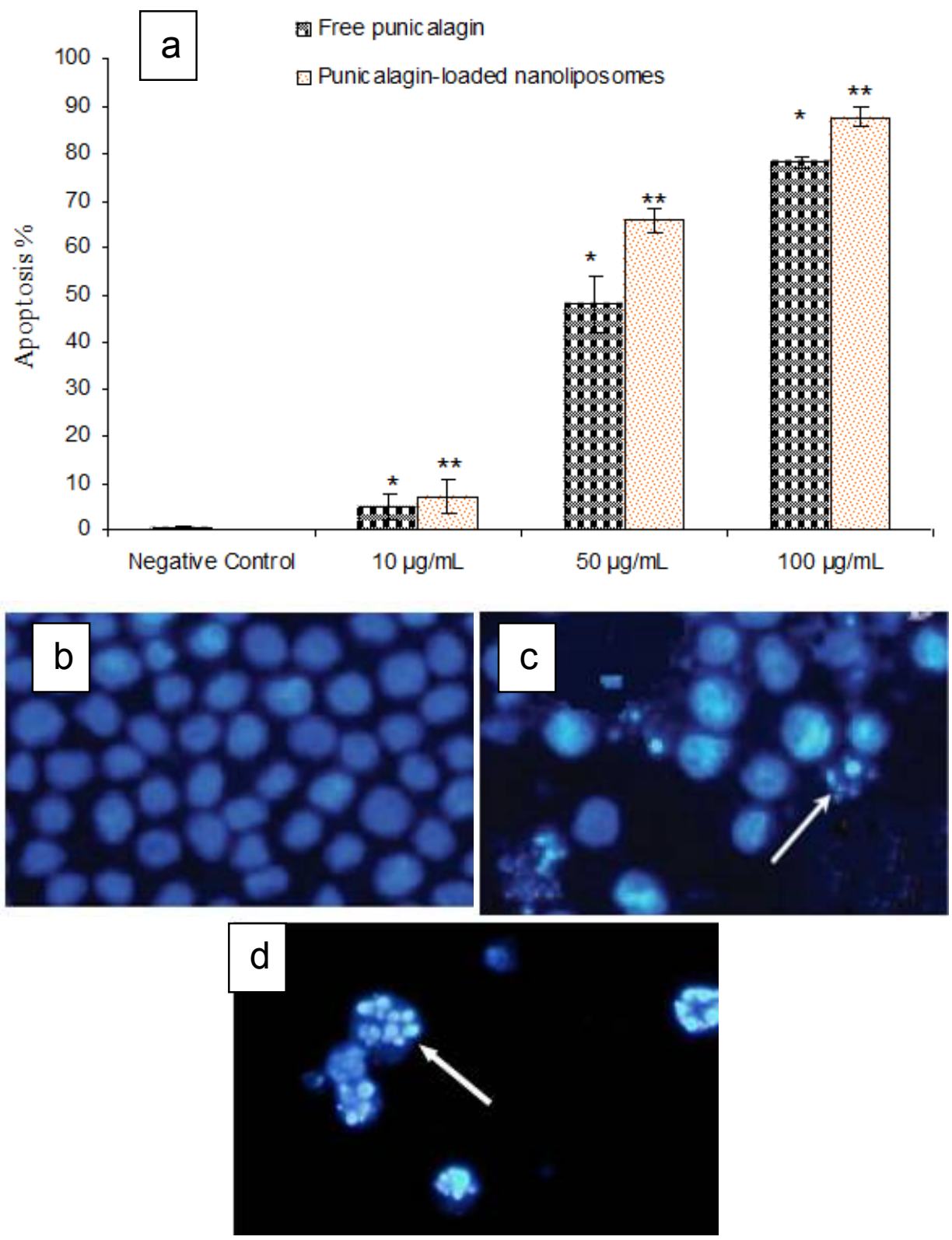

Figure 4: Extent of apoptosis in K562 cells after treatment with punicalagin in the free and nanoliposomal forms (a). Compared to control cells (b), fragmented or condensed nuclei indicative of apoptosis could be observed in the punicalagin-treated cells with free (c) and nanoliposomal forms (d), as arrows indicate. Data represent mean \pm standard deviation from three independent experiments $\left({ }^{*} p<0.05\right.$ and $\left.{ }^{* *} p<0.001\right)$ 
(a)

Punicalagin $(10 \mu \mathrm{g} / \mathrm{mL})$

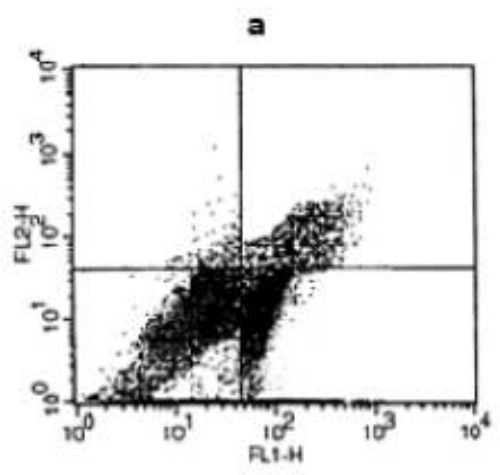

Quad \% Total

UL $\quad 2.62$

UR 8.05

LL $\quad 67.23$
Punicalagin $(50 \mu \mathrm{g} / \mathrm{mL})$

b

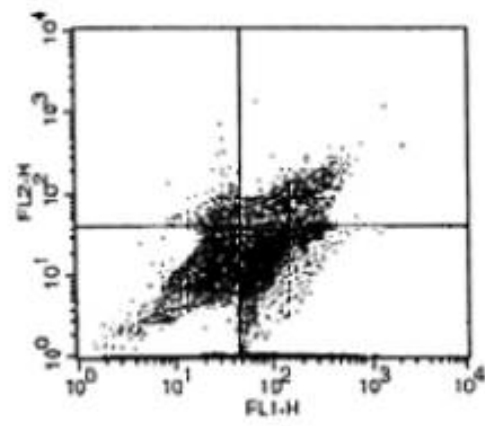

Quad \% Total

UL $\quad 4.18$

UR $\quad 12.68$

LL $\quad 26.41$
Punicalagin $(100 \mu \mathrm{g} / \mathrm{mL})$

c

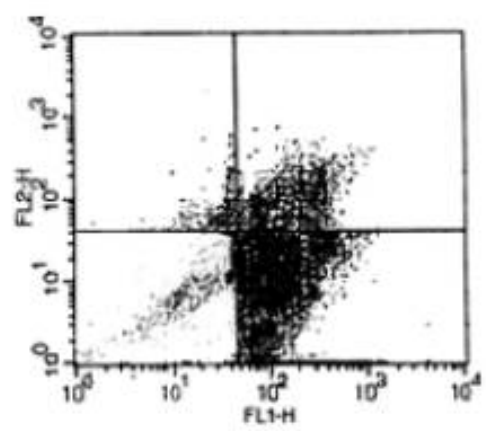

Quad \% Total

UL $\quad 6.05$

UR $\quad 14.28$

ㄴ․ $\quad 3.99$

(b)

Nanoliposomal punicalagin $(10 \mu \mathrm{g} / \mathrm{mL})$

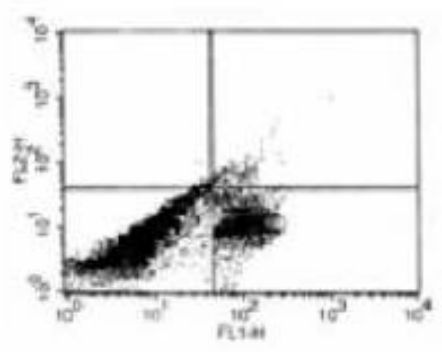

Quad \% Total
Nanoliposomal punicalagin $(50 \mu \mathrm{g} / \mathrm{mL})$

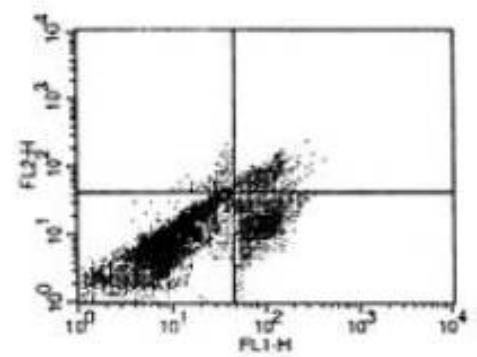

Quad \% Total

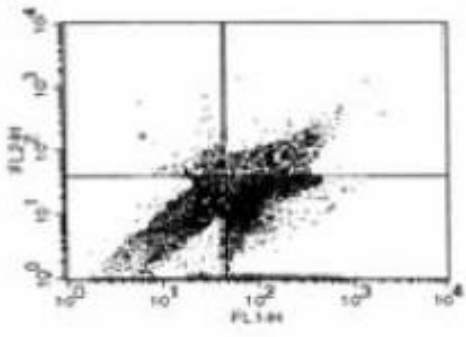

Quad \% Total

UL $\quad 1.06$

UL $\quad 5.24$

UL $\quad 7.18$

UR $\quad 15.41$

UR $\quad 11.69$

LL $\quad 37.59$

Figure 5: Representative FACS analysis of treated cells with 10, 50 and $100 \mu \mathrm{g} / \mathrm{mL}$ of punicalagin in the free (a), and loaded (b) forms after staining with Annexin V/PI. Lower Left (LL): AnnexinV PI', Lower Right (LR): Annexin $\mathrm{V}^{+} \mathrm{PI}^{-}$, Upper Right (UR): Annexin $\mathrm{V}^{+} \mathrm{PI}^{+}$, Upper Left (UL): Annexin $\mathrm{V}^{-} \mathrm{PI}^{+}$

Plant-derived compounds that can suppress telomerase activity might be potential candidates for cancer therapy because telomerase activity is found in a wide variety of cancer cells, including leukemia; this phenomenon could enhance resistance to apoptosis through multiple mechanisms $[8,9,15]$.
However, the main problem associated with the application of some plant-derived compounds is biological instability [13]. Previous studies showed that the incorporation of plant-derived compounds into nanoliposomes could overcome this limitation [14]. It has been reported that encapsulation of plant-derived materials in nano- 


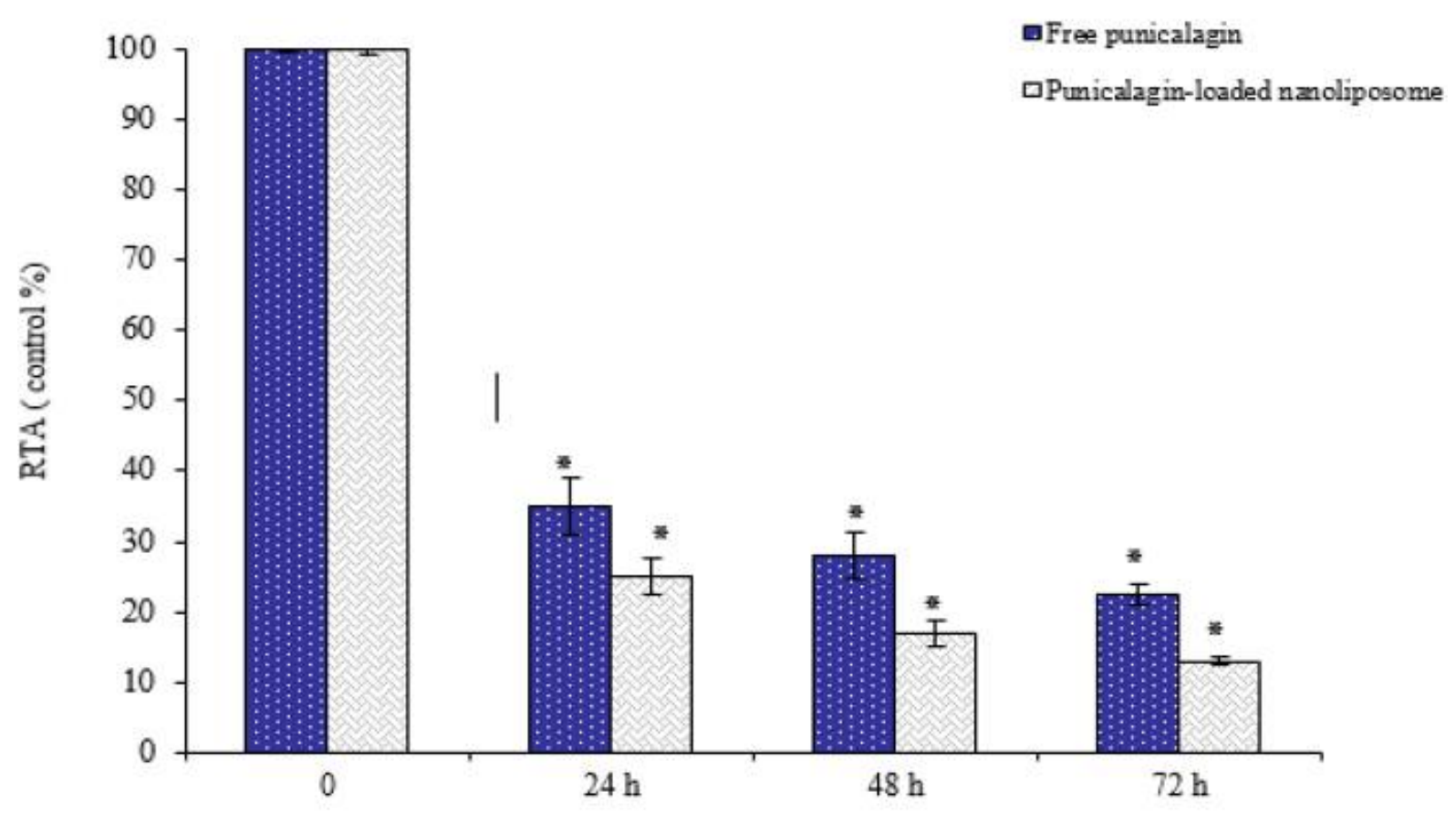

Figure 6: Concentration-dependent inhibition of relative telomerase activity by punicalagin in the free and loaded forms as detected by telomeric repeat amplification protocol enzyme-linked immunosorbent assay after $48 \mathrm{~h}\left({ }^{\star} P\right.$ $<0.05)$.

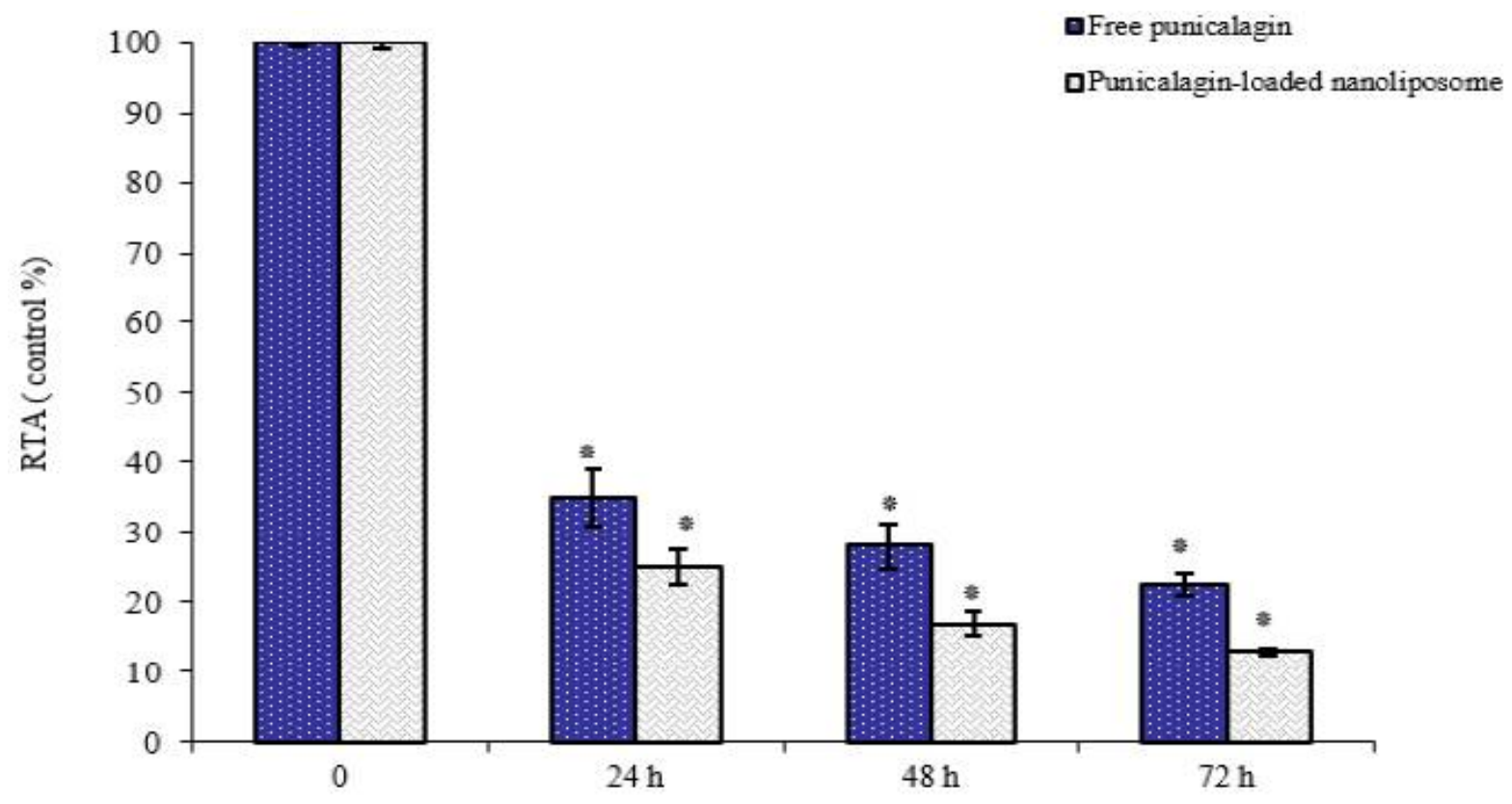

Figure 7: Time-dependent inhibition of relative telomerase activity by punicalagin in the free and encapsulated forms $(100 \mu \mathrm{g} / \mathrm{mL})$ as detected by telomeric repeat amplification protocol enzyme-linked immunosorbent assay $\left({ }^{*} p<0.05\right)$

liposomes can increase their stability and effectiveness [24].

In this study we found that punicalagin, in particular in the loaded form, significantly inhibited proliferation and telomerase activity in K562 cells in a concentration as well as time dependent manner. The data also indicated that anti-telomerase activity of punicalagin-loaded nanoliposomes in K562 cells was higher than those of free punicalagin.

Several hypotheses, including increased penetration of plant-derived compounds into cells and stability of encapsulated materials may explain the mechanism of enhanced anticancer 
efficacies of this nanoliposomal formulation [2530]. Our data showed a significant and positive correlation between telomerase inhibition and induction of apoptosis.

Similar anticancer activity had been reported in previous investigations with other liposomal natural plant products such as celastrol [25], epigallocatechin-3-gallate [24], gossypol [26], wagonin [27], berberin [28], curcumin [29] and tea polyphenol [30] in various cancer cell lines. Therefore, punicalagin and other effective plantderived agents in the free and encapsulated forms may be considered as promising strategy to develop new anticancer drugs.

\section{CONCLUSION}

Nanoliposomal punicalagin with acceptable characteristics has been successfully prepared. The findings of this study demonstrate that punicalagin, in the nanoliposomal form has potent anti-telomerase effect on K562 cells, and also time- and concentration-dependently inhibits cell growth in this cell line. Therefore, the developed nanoliposomal formulation may provide a basis for the future development of anti-telomerase agents for leukemia therapy.

\section{DECLARATIONS}

\section{Acknowledgement}

This study was supported by Islamic Azad University, Borujerd Branch, Iran. The authors would like to acknowledge the staff of the university for supporting this work.

\section{Conflict of Interest}

No conflict of interest associated with this work.

\section{Contribution of Authors}

The authors declare that this work was done by the authors named in this article and all liabilities pertaining to claims relating to the content of this article will be borne by them.

\section{REFERENCES}

1. Blackburn EH, Epel ES, Lin J. Human telomere biology: A contributory and interactive factor in aging, disease risks, and protection. Science 2015; 350: 1193-1198.

2. Teralı $K$, Yilmazer $A$. New surprises from an old favourite: The emergence of telomerase as a key player in the regulation of cancer stemness. Biochimie 2016; 121: 170-178.
3. Wang $X$, Hao MW, Dong $K$, Lin F, Ren JH, Zhang $H Z$. Apoptosis Induction Effects of EGCG in Laryngeal Squamous Cell Carcinoma Cells through Telomerase Repression. Arch Pharm Res 2009; 3: 1263-1269.

4. Heeg S. Variations in telomere maintenance and the role of telomerase inhibition in gastrointestinal cancer. Pharmgenomics Pers Med 2015; 8: 171-180.

5. Tian X, Chen B, Liu X. Telomere and Telomerase as Targets for Cancer Therapy. Appl Biochem Biotechnol 2010; 160: 1460-1472.

6. Nachajova M, Brany D, Dvorska D. Telomerase and the process of cervical carcinogenesis. Tumour Biol 2015; 36: 7335-7338.

7. Meena J, Rudolph KL, Günes C. Telomere Dysfunction, Chromosomal Instability and Cancer. Recent Results Cancer Res 2015; 200: 61-79.

8. Gharib A, Faezizadeh Z. In vitro anti-telomerase activity of novel lycopene-loaded nanospheres in the human leukemia cell line K562. Pharmacogn Mag 2014; 10 (Suppl 1): S157-63.

9. Wang $X$. Effects of allicin on both telomerase activity and apoptosis in gastric cancer SGC-7901 cells. World J Gastroenterol 2003; 9: 1930-1934.

10. Kim MS, Choi CS. HPLC analysis and in vitro study of the extract from Punica granatum peel. Rapid Comm Photosci 2013; 2: 28-30.

11. Saruwatari A, Okamura $S$, Nakajima $Y$, Narukawa $Y$, Takeda $T$, Tamura $H$. Pomegranate juice inhibits sulfoconjugation in Caco-2 human colon carcinoma cells. J Med Food 2008; 11: 623-628.

12. Kasimsetty SG, Bialonska D, Reddy MK, Thornton C, Willett KL, Ferreira D. Effects of pomegranate chemical constituents/intestinal microbial metabolites on CYP1B1 in 22Rv1 prostate cancer cells. J Agric Food Chem 2009; 57: 10636-10644.

13. Nuñez-Sánchez MA, García-Villalba R, Monedero-Saiz $T$, García-Talavera NV, Gómez-Sánchez MB, SánchezÁlvarez C, García-Albert AM, Rodríguez-Gil FJ, RuizMarín M, Pastor-Quirante FA, Martínez-Díaz F, YáñezGascón MJ, González-Sarrías A, Tomás-Barberán FA, Espín JC. Targeted metabolic profiling of pomegranate polyphenols and urolithins in plasma, urine and colon tissues from colorectal cancer patients. Mol Nutr Food Res 2014; 58: 1199-1211.

14. Koohi Moftakhari Esfahani M, Alavi SE, Akbarzadeh A, Ghassemi S, Saffari Z, Farahnak M, Chiani M. Pegylation of Nanoliposomal Paclitaxel Enhances its Efficacy in Breast Cancer. Trop J Pharm Res 2014; 13: 1195-1198.

15. A Gharib, Z Faezizadeh, M Godarzee. Preparation and characterization of nanoliposomal beta-cryptoxanthin and its effect on proliferation and apoptosis in human leukemia cell line K562. Trop J Pharm Res 2015; 14: 187-194.

16. Fang JY, Hwang TL. Enhancement of the transdermal delivery of catechins by liposomes incorporating anionic surfactants and ethanol. Int J Pharm 2006; 310:131-138. 
17. Gil MI, Tomás-Barberán FA, Hess-Pierce B, Holcroft DM, Kader AA. Antioxidant activity of pomegranate juice and its relationship with phenolic composition and processing. J Agric Food Chem 2000; 48: 4581-4589.

18. Bothun GD, Lelis A, Chen Y, Scully K, Anderson LE, Stoner MA. Multicomponent folate-targeted magnetoliposomes: design, characterization, and cellular uptake. Nanomedicine 2011; 7: 797-805.

19. Campling BG, Pym J, Baker HM, Cole SP, Lam YM. Chemosensitivity testing of small cell lung cancer using the MTT assay. Br J Cancer 1991; 63: 75-83.

20. Bradford MM. A rapid and sensitive method for the quantitation of microgram quantities of protein utilizing the principle of protein-dye binding. Anal Biochem 1976; 72:248-54.

21. Adams LS, Seeram NP, Aggarwal BB, Takada Y, Sand $D$, Heber $D$. Pomegranate juice, total pomegranate ellagitannins, and punicalagin suppress inflammatory cell signaling in colon cancer cells. J Agric Food Chem 2006; 54: 980-985.

22. Yang Y, Xiu J, Zhang L, Qin C, Liu J. Antiviral activity of punicalagin toward human enterovirus 71 in vitro and in vivo. Phytomedicine 2012; 20: 67-70.

23. Seeram NP, Adams LS, Henning SM, Niu Y, Zhang Y, Nair MG, Heber D. In vitro antiproliferative, apoptotic and antioxidant activities of punicalagin, ellagic acid and a total pomegranate tannin extract are enhanced in combination with other polyphenols as found in pomegranate juice. J Nutr Biochem 2005; 16: 360-367.

24. de Pace RC, Liu X, Sun M, Nie S, Zhang J, Cai Q, Gao W, Pan X, Fan Z, Wang S. Anticancer activities of (-)- epigallocatechin-3-gallate encapsulated nanoliposomes in MCF7 breast cancer cells. J Liposome Res 2013; 23 : 187-196.

25. Wolfram J, Suri K, Huang $Y$, Molinaro R, Borsoi C, Scott $B$, Boom K, Paolino D, Fresta M, Wang J, Ferrari M, Celia $C$, Shen $H$. Evaluation of anticancer activity of celastrol liposomes in prostate cancer cells. J Microencapsul 2014; 31: 501-507.

26. LiH, Piao L, Xu P, Ye W, Zhong S, Lin SH, Kulp SK, Mao $Y$, Cho $Y$, Lee LJ, Lee RJ, Lin YC. Liposomes containing (-)-gossypol-enriched cottonseed oil suppress $\mathrm{BCl}-2$ and $\mathrm{BCl}-\mathrm{xL}$ expression in breast cancer cells. Pharm Res 2011; 28: 3256-3264.

27. Tian J, Wang L, Wang L, Ke X. A wogonin-loaded glycyrrhetinic acid-modified liposome for hepatic targeting with anti-tumor effects. Drug Deliv 2014; 21 : 553-559.

28. Ma X, Zhou J, Zhang CX, Li XY, Li N, Ju RJ, Shi JF, Sun MG, Zhao WY, Mu LM, Yan Y, Lu WL. Modulation of drug-resistant membrane and apoptosis proteins of breast cancer stem cells by targeting berberine liposomes. Biomaterials 2013; 34: 4452-4465.

29. Hasan M, Belhaj N, Benachour H, Barberi-Heyob M, Kahn CJ, Jabbari E, Linder $M$, Arab-Tehrany $E$. Liposome encapsulation of curcumin: physico-chemical characterizations and effects on MCF7 cancer cell proliferation. Int J Pharm 2014; 461: 519-528.

30. Fang JY, Lee WR, Shen SC, Huang YL. Effect of liposome encapsulation of tea catechins on their accumulation in basal cell carcinomas. J Dermatol Sci 2006; 42: 101-109. 